\title{
Abordagem Multimodal: um olhar para os Livros Didáticos de Química
}

\section{Multimodal approach: a look at Chemistry Textbooks}

\author{
Júlia C. Freitas e Ana Luiza de Quadros
}

RESUMO: O entendimento de um conteúdo ou de conceitos depende diretamente da comunicação entre quem ensina e os aprendizes. Para melhorar essa comunicação e também a construção de significados tem sido enfatizada uma maior atenção para a multimodalidade, ou seja, para o uso e a integração de diferentes modos semióticos. Neste trabalho analisamos os modos semióticos presentes em livros didáticos de Química e como eles estão relacionados entre si. Para isso selecionamos uma parte do conteúdo relativo à Termoquímica presente em três coleções didáticas do Programa Nacional do Livro Didático. Nas obras analisadas observamos uma diversidade de modos semióticos, mas a relação entre eles necessita de uma atenção maior por parte dos autores. As imagens se destacaram entre esses modos, seguindo uma tendência favorecida pelas tecnologias disponíveis. Esses resultados trazem implicações para professores e autores, pois à medida que se entende a importância de se relacionar esses modos, essas relações podem ser fomentadas nas aulas e nos materiais didáticos.

Palavras-chave: multimodalidade, livro didático, química, construção de significados

\begin{abstract}
We start from the idea that the understanding of a content or concept depends directly on the communication between who teaches and who learns. Multimodality has been used to improve this communication and construct meanings about what is communicated, in other words, the use and integration of multiple semiotic modes. This work analyzes the semiotic modes present in Chemistry textbooks and how they are related to each other. For such, we selected a section of the content related to Thermochemistry present in three textbook collections of Brazil's National Textbook Program. The analyzed works presented a diversity of semiotic modes, but the relationship between them requires greater attention from the authors. Figures stood out among these modes, following a trend favored by the available technologies. These results have implications for both teachers and authors; as the importance of relating these modes is understood, these relationships can be fostered in classes and teaching materials.
\end{abstract}

Keywords: multimodality, textbook, chemistry, construction of meanings

Júlia Campos Freitas (julia_campos_f@ @otmail.com), licenciada em Química e professora da Educação Básica, ministrando a disciplina de Química. Durante a graduação foi bolsista de Iniciação científica e do PIBID. Atualmente é mestranda no programa de Mestrado Profissional Educação e Docência pela Faculdade de Educação da UFMG. Belo Horizonte, MG - BR. Ana Luiza de Quadros (ana.quadros @ uol.com.br), doutora em Educação e professora de Ensino de Química na Universidade Federal de Minas Gerais, atuando no Programa de Pós-graduação em Educação. Belo Horizonte, MG - BR.

Recebido em 21/08/2020, aceito em 10/02/2021

A seção "Cadernos de Pesquisa" é um espaço dedicado exclusivamente para artigos inéditos (empíricos, de revisão ou teóricos) que apresentem profundidade teórico-metodológica, gerem conhecimentos novos para a área e contribuições para o avanço da pesquisa em Ensino de Química. 
Ao tratar da insatisfação geral com os resultados do Ensino de Ciências ao redor do mundo, Millar (2003, p. 74) afirma que "a maior causa dessa insatisfação é o acúmulo de evidência [...] de que pouco conhecimento científico seja de fato assimilado e compreendido pela maior parte dos estudantes". Tendo em vista esse cenário, diferentes propostas de ensino têm surgido com o intuito de produzir mais aprendizagem.

Um breve olhar na literatura especializada já permite perceber a presença de diversos trabalhos que defendem abordagens diferenciadas para o Ensino de Ciências, tais como o ensino por investigação (Trivelato; Tonidandel, 2015; Zômpero; Laburú, 2011; Munford; Lima, 2007), o uso adequado da experimentação (Guimarães et al., 2018; Giordan, 1999), a abordagem CTS (Santos; Mortimer, 2000; Pinheiro; Silveira; Bazzo, 2007; Strieder, 2012), entre outras possibilidades que certamente apresentam vantagens quando comparadas com o ensino por meio de transmissão de informações, sem uma atenção especial para como essas informações são significadas pelos estudantes.

Partimos da ideia de que o entendimento de um conteúdo ou de conceitos depende diretamente da comunicação entre quem ensina e os aprendizes. Nessa perspectiva, estudos têm apontado para a multimodalidade (Kress et al., 2001; Kress, 2010; Alves, 2011; Silva; Souza; Cipriano, 2015; Mortimer; Quadros, 2018) como forma de melhorar a comunicação em sala de aula. A multimodalidade baseia-se na combinação e integração de diferentes modos semióticos em situações comunicativas, além do modo verbal (fala e escrita). A diversidade de modos semióticos pode estar presente tanto nas interações discursivas em sala de aula quanto no material didático escrito.

Desenvolvemos este trabalho com o objetivo de analisar a presença de multimodos e como esses diferentes modos estão relacionados entre si em diferentes livros didáticos de Química do Ensino Médio. Tendo em vista a centralidade atribuída aos livros didáticos no contexto educacional, acreditamos que este trabalho tem relevância para as questões que envolvem o Ensino de Ciências, uma vez que a multimodalidade em textos escritos pode contribuir para a significação de ideias e conceitos.

\section{Referencial Teórico}

Neste trabalho dirigimos a nossa atenção para o papel dos livros didáticos usados na disciplina de Química do Ensino Médio e o da multimodalidade na promoção da interação entre os estudantes e o conteúdo. Assim, dividimos essa seção em duas partes: o livro didático (a) e os modos semióticos/ multimodalidade (b).

\section{a) Livro didático}

O livro didático tem se revelado como recurso de grande importância no âmbito escolar, devido ao fato de ser uma ferramenta que auxilia tanto os professores, quanto os estudantes nos processos de ensino e de aprendizagem. Carneiro et al.
(2005) afirmam que a centralidade firmada em decorrência do uso do livro didático confere a ele diferentes funções, tais como fonte de organização, desenvolvimento e avaliação do trabalho pedagógico pelo professor e também como elemento importante na relação entre o estudante e a disciplina.

Ao tratar do conteúdo relativo a "Efeito Estufa e Aquecimento Global", Lobato et al. (2009) comentam a importância do livro didático na própria constituição do conteúdo programático de uma disciplina. Sobre isso eles afirmam que:

Pela disponibilidade e/ou facilidade de acesso ao livro didático, percebe-se que os conteúdos selecionados pelos autores acabam sendo, em muitos casos, os mesmos conteúdos que o professor desenvolve em sala de aula. Por este motivo, livros didáticos têm sido compreendidos como agentes determinantes de currículos, limitando a inserção de novas abordagens e possibilidades de contextualização do conhecimento (Lobato et al., 2009, p. 2).

Assim como Lobato et al. (2009), diferentes pesquisadores desenvolveram estudos acerca dos livros didáticos voltados para o Ensino de Ciências. Trabalhos como os de Mortimer (1988), Lajolo (1996), Amaral e Megid Neto (1997) e Megid Neto e Fracalanza (2003) se debruçaram a desvendar aspectos relativos tanto ao desenvolvimento desses recursos ao longo do tempo e à qualidade deles, quanto a problemas e as possíveis soluções identificadas.

No âmbito do Ensino de Ciências, estudos revelam que a maior parte dos livros didáticos se sedimenta na apresentação pragmática do conteúdo a ser transmitido para os estudantes. Frison et al. (2009, p. 7) enfatizam que "a maioria dos livros didáticos apresenta uma ciência descontextualizada, separada da sociedade e da vida cotidiana, e concebem o método científico como um conjunto de regras fixas para encontrar a verdade". Esse cenário ainda pode ser identificado em muitas obras desenvolvidas para o Ensino de Química, embora existam programas e documentos oficiais nacionais que recomendem um ensino mais contextualizado.

No Brasil, o Programa Nacional do Livro Didático (PNLD), que tem como objetivo avaliar e fornecer obras didáticas e de apoio à educação, de forma gratuita para os estudantes de escolas públicas de todo o país, destaca a relevância de se estabelecer uma associação entre o Ensino de Ciências e os aspectos sociais, tecnológicos e culturais. Nessa perspectiva, o PNLD (Brasil, 2018, p. 9) afirma que "o livro didático para o Ensino Médio deve ser inserido, constituindo-se como mais uma ferramenta de apoio à construção dos processos educativos, com vista a assegurar a articulação das dimensões ciência, cultura, trabalho e tecnologia".

As obras aprovadas no programa passam por uma análise, coordenada pelo Ministério da Educação, com base em critérios por ele estabelecidos. Dentre as diversas exigências 
feitas, estipula-se que os livros didáticos devem apresentar informações adequadas, claras e corretas, além de atualizadas (Brasil, 2018). Após a avaliação e a seleção de um conjunto de obras, os professores de cada instituição devem escolher um livro didático, dentre os que foram aprovados, que acreditam ser mais adequado para a realidade na qual se inserem.

No edital vigente (Brasil, 2019) para a escolha das obras a serem usadas entre 2021 e 2024 há um destaque para os projetos integradores, que enfatizam a relação entre Ciência, Tecnologia, Engenharia, Artes e Matemática (Science, Technology, Engineering, Arts e Mathematics - STEAM), o protagonismo juvenil, a mediação de conflitos e a presença da mídia na educação. As mudanças esperadas a partir das orientações contidas nesse edital (que derivam da BNCC) têm início na produção do material didático. Com isso, afirmamos que todo o processo de inserção do livro didático nas escolas e os diferentes estudos realizados envolvendo esse tipo de material reforçam a importância desse recurso no contexto escolar.

Tendo em vista a importância do livro didático como material de apoio a estudantes e professores, torna-se relevante promover análises desses recursos, identificando as diferentes alternativas oferecidas pelos autores, com o objetivo de facilitar o processo de compreensão das informações transmitidas. Considerando nosso objetivo de identificar a presença de multimodos e a relação entre os diferentes modos no livro didático, o item seguinte trata da multimodalidade e dos modos semióticos.

\section{b) Modos semióticos e multimodalidade}

Para que a aprendizagem no Ensino de Ciências ocorra de forma relevante é importante que os estudantes sejam capazes de dar significado aos fenômenos e conceitos trabalhados no contexto escolar. O professor tem, portanto, um papel importante nesse processo e deve estabelecer meios que auxiliem o estudante na compreensão das ideias transmitidas. Para compreender de que forma a multimodalidade pode contribuir para melhorar a dinâmica escolar faz-se necessário explicitar de que maneira os significados são construídos em âmbito geral, não apenas em sala de aula.

A comunicação em uma sociedade se dá de diferentes formas e, possivelmente, a fala é o instrumento mais comum para se estabelecer uma relação com significados entre sujeitos. Contudo, existem diferentes meios de se estabelecer um processo comunicativo, conforme enfatizam Kress e colaboradores (2001, p. 43), ao explicarem o que nomeiam como "modos". Eles afirmam que:

[...] o meio é moldado e organizado em uma série de sistemas de construção de significado, a fim de articular os significados exigidos pelas necessidades sociais de diferentes comunidades; isso é o que nós chamamos modos. Todos os modos fazem significados de maneira diferentes, e os significados feitos nem sempre estão disponíveis ou são entendidos por todos os leitores (Tradução nossa).

A semiótica social defende que as diferentes formas de comunicação para construção de um significado se dão segundo as características de uma determinada sociedade. Admite-se como um modo, portanto, um recurso semiótico capaz de dar sentido, que seja socialmente modelado e culturalmente estabelecido (Kress, 2010).

Para Norris (2004), os modos semióticos usados na comunicação têm por base a forma como são percebidos. Nesse caso, os modos podem ser considerados como auditivos (fala, música, som, efeitos sonoros etc.); visuais (olhar, impressão, imagem etc.); de ação (gesto, postura, movimento, expressão facial, contato e manipulação de objetos/modelos, ações mediadas com livros, projeção em tela etc.); e ambientais (proxêmica, layout etc.). Para este trabalho, que trata da presença de modos semióticos em um texto escrito, nem todos os descritos por Norris (2004) podem ser analisados.

Assim como a comunicação entre sujeitos de uma sociedade tem seus significados produzidos segundo os modos compreendidos devido às características semióticas de uma comunidade (Mortimer; Quadros, 2018; Joyce; Feez, 2018), a linguagem científica também depende do reconhecimento de seus modos pelos interlocutores. A comunidade científica, incluindo os educadores, desenvolve recursos semióticos reconhecidos apenas por essa coletividade e, como consequência, ser capaz de reconhecer tais modos faz parte do processo de aprender Ciência (Kress et al., 2001).

Ao observar o contexto de comunicação estabelecido no ensino e na aprendizagem, constata-se que a linguagem verbal (escrita e fala) aparece como o modo mais utilizado, enquanto outros modos não-verbais, tais como imagens, gestos e ações, são considerados, em muitos casos, apenas formas de ilustrar o que se deseja transmitir (Kress et al., 2001). Contudo, a linguagem não-verbal vem ganhando espaço nos processos de comunicação em nossa sociedade. Podemos verificar essa tendência em anúncios televisivos que ofertam produtos destacando sua imagem, ainda que associado a um texto sobre ele; na relação estabelecida entre duas pessoas que se comunicam por olhares e gestos; em gráficos representando a intenção de votos para candidatos na próxima eleição; e em muitos outros momentos do cotidiano de uma sociedade.

Segundo Alves (2011), a linguagem verbal escrita tem características que a diferenciam da linguagem verbal falada. Nesse sentido, ele trata a temporalidade dos diferentes modos semióticos que podem ser estabelecidos no texto escrito. Alves (2011, p. 21), em seu estudo sobre esse aspecto referente a linguagem verbal, pondera que:

No caso da fala, a dependência do tempo é incontestável, uma vez que uma palavra só pode ser dita após a outra e o ouvinte recebe e significa, também, 
uma palavra após a outra. Na escrita, o leitor pode perceber as várias palavras ao mesmo tempo, o que é também uma característica dos modos visuais, pois elas estão dispostas sobre a folha impressa. [...]. Uma diferença importante entre os modos verbais orais e escritos é a existência, nesses últimos, de uma infinita gama de possíveis caminhos de leitura. $\mathrm{O}$ leitor pode retroceder na leitura de parágrafos anteriores e voltar a refletir sobre eles por quanto tempo quiser ou puder.

No texto escrito, os modos de comunicação visual (fotografias, desenhos, gráficos, representações e outros) geralmente estão bastante presentes. Eles são independentes do tempo, uma vez que todos esses elementos estão disponíveis simultaneamente e de forma permanente para o leitor (Alves, 2011). Nesse caso, o leitor tem a possibilidade de consultar as informações novamente, uma vez que elas se mantêm disponíveis. Isso não ocorre em outros contextos, tais como na utilização do modo verbal na fala, pois uma vez que as informações são ditas, não é possível retornar àquilo que foi dito, que já compõe parte de um tempo passado. Em livros didáticos, foco deste trabalho, alguns modos visuais e o modo verbal escrito costumam representar uma importante fonte de informações permanentes para o leitor.

Vale lembrar que "cada um desses modos possui potencialidades e limitações distintas para a comunicação, resultantes tanto do meio material no qual é veiculado, quanto do trabalho que uma determinada cultura realizou sobre ele" (Alves; Mortimer, 2017, p. 3). Desta forma é esperado que ao propor um livro didático o autor leve em consideração a maneira como os modos utilizados contribuem para a comunicação com o leitor, dando significado à informação ali presente.

No Ensino de Ciências os gestos, a fala, a escrita, a proxêmica e o olhar são os principais modos semióticos utilizados em sala de aula, muitas vezes concomitantemente. Nesse sentido, é aconselhável que esses modos não sejam analisados separadamente (Mortimer; Quadros, 2018).

Assim como na comunicação em sala de aula, um recurso didático também é permeado por diferentes modos. Os livros de Ciências, por exemplo, frequentemente apresentam diferentes representações, tais como figuras, desenhos, gráficos, tabelas, diagramas e texto escrito, caracterizando a presença tanto da linguagem verbal, quanto da linguagem não verbal (Alves, 2011). Ao introduzir diferentes modos, os autores podem auxiliar o estudante no processo de significação das informações contidas no livro didático, as quais devem ser adequadas ao público-alvo do material, para que a comunicação seja estabelecida de forma eficaz.

Os livros didáticos são meios de comunicação que se utilizam da comunicação multimodal, a qual se dá a partir do momento em que diferentes modos semióticos são utilizados simultaneamente para produzir um significado. Segundo Quadros, Pena e Botelho (2020, p. 16), a "multimodalidade representa, hoje, tanto um fenômeno da comunicação humana quanto um campo diversificado e crescente de pesquisa, que examina os diversos modos que as pessoas usam para se comunicar e se expressar".

Cada modo de comunicação e de representação produz significados de forma independente, mas quando mais de um modo é utilizado simultaneamente, eles tendem a formar uma teia de relações, permitindo ampliar e/ou aprimorar os significados que se deseja transmitir (Kress et al., 2001). Portanto, a multimodalidade e a relação entre os diferentes modos se mostram importantes na construção de significado para as informações que o livro didático apresenta.

\section{Metodologia}

De acordo com Bogdan e Biklen (2003), a pesquisa que ocorre em um ambiente natural, que se utiliza de dados descritivos, que fornece atenção para o processo e o seu significado é caracterizada como qualitativa. Neste trabalho analisamos livros didáticos buscando os modos semióticos presentes e as relações entre eles e, apesar de quantificarmos algumas dessas relações, os dados coletados foram predominantemente descritivos. Assume características de pesquisa bibliográfica, uma vez que investiga dados presentes em livros didáticos.

Para que pudéssemos identificar os diferentes modos de comunicação e analisar a relação entre eles em livros didáticos de Química do Ensino Médio, definimos como objeto de estudo três livros didáticos aprovados pelo PNLD de 2018. Conforme mencionado anteriormente, trata-se de um programa criado pelo governo federal, sob responsabilidade do Ministério da Educação, que organiza a avaliação, a seleção e a distribuição das coleções didáticas para as escolas da rede pública de todo o Brasil. Selecionamos três das cinco coleções de livros didáticos aprovados pelo PNLD 2018, sendo uma delas de autores que tradicionalmente têm participado dos debates envolvendo o ensino de Química e também dos eventos da área no Brasil e que não têm um envolvimento em termos de pesquisa com o tema multimodalidade e outras duas coleções escolhidas aleatoriamente entre as demais disponíveis.

No Quadro 1 listamos as obras analisadas e seus respectivos autores.

Após a escolha dos livros didáticos, delimitamos o campo de investigação. Para isso, selecionamos o conteúdo de Termoquímica, por detectarmos que os textos que abordavam esse tema empregavam diversos modos semióticos. Acreditamos que essa característica permitiria que o estudo se mostrasse rico em suas análises devido à variedade de relações identificadas entre os diferentes modos presentes. Embora tivéssemos selecionado apenas um dos conteúdos, um novo recorte precisou ser feito, para viabilizar este estudo. O foco se estabeleceu na abordagem de conteúdos iniciais, tais como energia, calor e temperatura, mas se estendeu também a conceitos mais específicos da área, a exemplo dos processos 
Quadro 1: Lista dos livros didáticos analisados.

\begin{tabular}{|c|c|c|c|}
\hline Denominação & Título & Autores & Edição \\
\hline Livro 1 & Química Cidadã & Wildson Santos e Gerson Mól & 2016 \\
\hline Livro 2 & Ser Protagonista & $\begin{array}{c}\text { Julio C. F. Lisboa, Aline T. Bruni, Ana Luiza P. Nery, Paulo A. G. Bianco, } \\
\text { Rodrigo M. Liegel, Simone G. Ávila, Simone J. Ydi, Solange, W. Locatelli } \\
\text { e Vera L. M. Aoki }\end{array}$ & 2016 \\
\hline Livro 3 & Vivá & Vera L. D. Novais e Murilo T. Antunes & 2016 \\
\hline
\end{tabular}

endotérmicos e exotérmicos, entalpia, calor específico e calor envolvido em uma transformação. Com isso, não foram analisados, em nenhum dos livros, os trechos referentes a cálculos de entalpia específicos de cada tipo de calor envolvido em um fenômeno (Ex.: calor de formação, calor de combustão etc.). O Quadro 2 indica o espaço, em páginas, delimitado em cada um dos livros didáticos.

Quadro 2: Fragmentos selecionados nos livros didáticos analisados.

\begin{tabular}{|c|c|c|}
\hline Livro 1 & Livro 2 & Livro 3 \\
\hline Págs. 231-263 & Págs. 50 - 60 & Págs. 94 - 106 \\
\hline
\end{tabular}

A análise de cada um dos livros revelou uma grande disparidade na quantidade de páginas utilizadas em cada um deles para abordar um mesmo conteúdo. Observamos também que o Livro 1 opta por uma abordagem mais dialógica, com indicação de que diferentes pontos de vista sejam considerados. Nessa obra, o conteúdo é permeado por textos, trabalhos, pesquisas e faz relações com aspectos sociais, históricos e tecnológicos. Em contrapartida, os livros 2 e 3 se mostram mais sucintos, focando na apresentação do conteúdo de forma mais objetiva.

Posteriormente à demarcação do trecho a ser analisado em cada livro, foi realizada uma leitura minuciosa dos textos para levantamento dos modos de comunicação presentes. Em seguida ao reconhecimento dos modos semióticos existentes, foi examinada a frequência de cada um deles e as relações multimodais feitas pelos autores das obras.

Em um primeiro olhar para os livros didáticos, fizemos a subdivisão dos modos Imagem, Escrita, Equações (Mortimer; Quadros, 2018), Gráficos e Tabelas. Por comodidade de análise, optamos por considerar os textos/figuras no formato de "boxe"1 como um modo semiótico. Os modos semióticos encontrados estão sintetizados na Figura 1, a seguir.

Como modo "Gráfico" foram consideradas todas as representações visuais de dados e informações numéricas usadas nos livros e como "Tabela" incluem-se as tabelas e os quadros, uma vez que os autores, algumas vezes, utilizam um dado numérico central em um quadro, o que, segundo norma da Associação Brasileira de Normas Técnicas (ABNT, 2011, p. 4) seria característica de uma tabela.
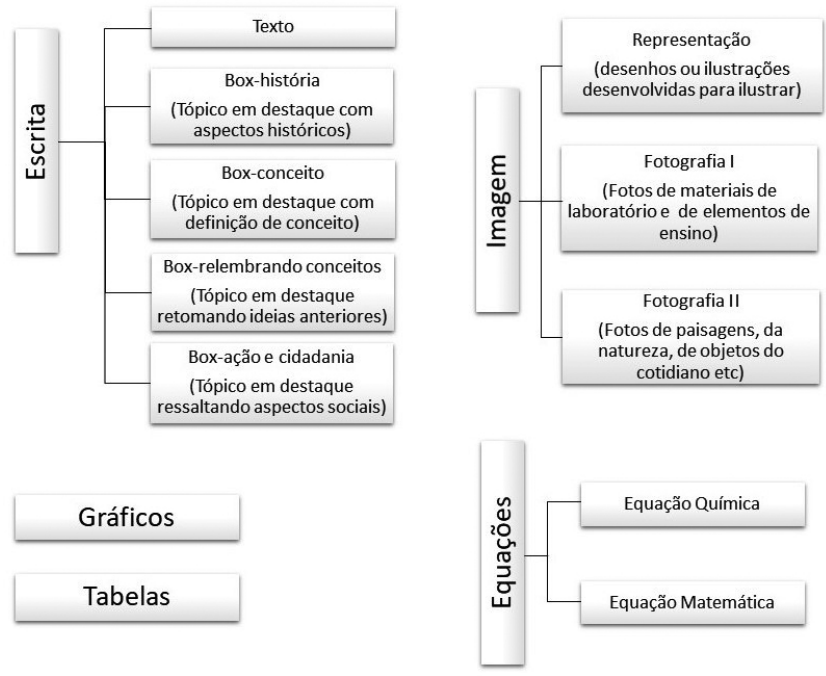

Figura 1: Modos semióticos definidos para a análise. Fonte: autores.

Após a demarcação dos modos semióticos presentes nos textos, elaboramos as possíveis relações a serem estabelecidas entre eles, em um contexto multimodal. Essas relações, bem como a explicação de cada uma delas, está melhor detalhada no Quadro 3.

Para facilitar a análise das relações entre os modos presentes nos textos, eles foram divididos em pares. O modo texto é predominante nos livros, sendo o alicerce em que se sustenta a comunicação do conteúdo e, por isso, aparece em seis das oito relações encontradas. No Quadro 3 descrevemos as possibilidades de relações (ou não relações), entre aquelas presentes nos livros, para cada um dos pares.

Definidos os modos e as possíveis relações entre eles, cada livro foi analisado segundo essa perspectiva multimodal. Para isso, no segundo momento de análise, em cada página do livro foram identificados os modos existentes, o conteúdo abordado e as relações estabelecidas entre esses modos.

\section{Resultados e Discussão}

Fizemos, inicialmente, um olhar mais panorâmico, com a intenção de identificar os modos semióticos presentes nas páginas selecionadas de cada uma das obras, que correspondiam ao conteúdo introdutório de Termoquímica, e a frequência com

${ }^{1}$ Embora os autores ainda usem a palavra "box", optamos pelo uso de "boxe". (ver Nocoleti, T. Box ou Boxe?. In: http://www3.uol.com.br/ qualidadeconteudo/portugues/box-ou-boxe.jhtm). Acesso em 04/02/2021. 
Quadro 3: Relações entre modos semióticos presentes nas obras analisadas.

\begin{tabular}{|c|c|c|}
\hline Pares de modos & Relação & Explicação \\
\hline \multirow{4}{*}{ Texto e Imagem } & Relação direta & A imagem é relacionada com o texto, com referência entre eles. \\
\hline & Relação indireta & A imagem é explicada no texto, sem referência entre eles. \\
\hline & Imagem como exemplo & $\begin{array}{l}\text { O texto faz referência à imagem, mas não a explica. (Ex: veja a imagem à } \\
\text { direita). }\end{array}$ \\
\hline & Imagem ilustrativa & $\begin{array}{l}\text { Imagem e texto não estabelecem relação explícita entre si, ou seja, o texto } \\
\text { não cita e não explica a imagem. }\end{array}$ \\
\hline \multirow{3}{*}{ Texto e Gráfico } & Relação direta & $\begin{array}{l}\text { O gráfico é relacionado com o texto, com referência entre eles. Esses modos } \\
\text { se complementam. }\end{array}$ \\
\hline & Relação indireta & $\begin{array}{l}\text { Gráfico e texto se complementam, mas sem que o texto cite o gráfico. Ainda } \\
\text { assim, o texto promove uma discussão dos dados presentes no gráfico. }\end{array}$ \\
\hline & Gráfico ilustrativo & $\begin{array}{l}\text { Gráfico e texto não estabelecem relação explícita entre si, ou seja, o texto } \\
\text { não cita o gráfico. }\end{array}$ \\
\hline \multirow{2}{*}{ Texto e Equação Química } & Relação direta & $\begin{array}{l}\text { A equação química representa um fenômeno que é referenciado no texto } \\
\text { que a acompanha. }\end{array}$ \\
\hline & Relação indireta & $\begin{array}{l}\text { O texto não faz referência explícita ao fenômeno retratado na equação. A } \\
\text { equação é uma exemplificação. }\end{array}$ \\
\hline \multirow{2}{*}{ Texto e Equação Matemática } & Relação completa & $\begin{array}{l}\text { Cada termo constituinte da equação matemática é devidamente identificado } \\
\text { no texto que a acompanha. }\end{array}$ \\
\hline & Relação incompleta & $\begin{array}{l}\text { O texto não identifica ou identifica apenas parcialmente cada termo } \\
\text { constituinte da equação matemática a que se refere. }\end{array}$ \\
\hline \multirow[b]{2}{*}{ Texto e Tabela } & Relação direta & A tabela é citada no texto, que discute os dados presentes na tabela. \\
\hline & Tabela ilustrativa & $\begin{array}{l}\text { Os dados presentes na tabela não são discutidos ao longo do texto, dando } \\
\text { a ela um caráter ilustrativo. }\end{array}$ \\
\hline \multirow[t]{2}{*}{ Texto e Boxe } & Boxe referenciado no texto & $\begin{array}{l}\text { O boxe (história, conceito, relembrando conceito ou ação/cidadania) } \\
\text { apresenta aspectos relacionados com o tema trabalhado no texto e o texto } \\
\text { faz menção a ele. }\end{array}$ \\
\hline & Boxe não referenciado no texto & $\begin{array}{l}\text { O boxe apresenta aspectos relacionados com o tema trabalhado no texto, } \\
\text { mas não é referenciado nele. }\end{array}$ \\
\hline \multirow{2}{*}{ Gráfico e Imagem } & Relação direta & $\begin{array}{l}\text { Gráfico e imagem representam o mesmo fenômeno, com referência de um } \\
\text { para outro. (não ocorreu) }\end{array}$ \\
\hline & Relação indireta & $\begin{array}{l}\text { Gráfico e imagem representam o mesmo fenômeno, sem referência de um } \\
\text { para outro. (ocorreu uma única vez) }\end{array}$ \\
\hline \multirow{2}{*}{ Gráfico e Equação Química } & Relação direta & $\begin{array}{l}\text { Gráfico e equação química representam o mesmo fenômeno, com referência } \\
\text { entre eles. (não ocorreu) }\end{array}$ \\
\hline & Relação indireta & $\begin{array}{l}\text { Gráfico e equação química representam o mesmo fenômeno, sem referência } \\
\text { entre eles. (uma única vez) }\end{array}$ \\
\hline
\end{tabular}

que foram usados. Em seguida, dirigimos um olhar mais específico para as relações estabelecidas entre os diferentes modos. Assim, nossos resultados se dividem nesses dois agrupamentos.

\section{a) Os modos semióticos presentes}

A quantidade de páginas usadas para tratar do assunto analisado - 33, 11 e 13, respectivamente - foi bem diferente entre um livro e outro. Para construir uma ideia mais adequada desses modos, optamos por apresentá-los individualmente e não em grupos. O Quadro 4 lista a ocorrência de cada um dos modos. Ressaltamos que chamamos de "texto" toda descrição de conteúdo que não se encontra em caixas tipo boxe (como é o caso do boxe-conceito). Esse modo (escrito) não foi quantificado por ser, como já dissemos, o alicerce em que se sustenta a comunicação do conteúdo, estabelecida com o estudante. Quantificamos os demais modos como inserções dentro do modo texto.

Podemos perceber que em cada uma das obras são enfatizados os modos considerados mais importantes para comunicar um dado conhecimento. Assim, o Livro 1 usa preferencialmente o modo imagem, principalmente "Fotografia II", que traz paisagens e objetos utilizados no cotidiano. Trata-se de um livro que apresenta um layout mais colorido quando comparado aos outros dois e que opta por inserir imagens em quase todos os tópicos, seja com o objetivo de apenas ilustrar e exemplificar, seja para auxiliar na compreensão de algum fenômeno 
Quadro 4: Modos de representação e recorrência nos livros didáticos analisados.

\begin{tabular}{|c|c|c|c|c|c|}
\hline \multicolumn{2}{|r|}{ Modos } & Livro 1 & Livro 2 & Livro 3 & Total \\
\hline \multirow{3}{*}{ Imagem } & Representação & 3 & 3 & 3 & 09 \\
\hline & Fotografia I (materiais de laboratório e elementos de ensino) & 6 & - & 2 & 08 \\
\hline & Fotografia II (paisagens, natureza, objetos do cotidiano). & 29 & 8 & 10 & 47 \\
\hline \multicolumn{2}{|l|}{ Gráfico } & 9 & 11 & 2 & 22 \\
\hline \multicolumn{2}{|l|}{ Tabela } & 4 & 1 & - & 5 \\
\hline \multirow{2}{*}{ Equações } & Equação Matemática & 5 & 3 & 2 & 10 \\
\hline & Equação Química & 6 & 5 & 12 & 23 \\
\hline \multirow{4}{*}{ Boxe } & Boxe-conceito & 11 & - & 2 & 13 \\
\hline & Boxe-história & 1 & 1 & - & 2 \\
\hline & Boxe-relembrando conceitos & - & 2 & - & 2 \\
\hline & Boxe-ação e cidadania & 1 & 2 & - & 3 \\
\hline \multicolumn{2}{|l|}{ Total } & 75 & 34 & 33 & -- \\
\hline \multicolumn{2}{|c|}{ Proporção modo/página } & 2,27 & 3,09 & 2,54 & -- \\
\hline
\end{tabular}

descrito no texto. No Livro 2 destaca-se o modo "Gráfico" e no Livro 3 o modo "Equação Química". Essas duas últimas obras apresentam uma organização mais conceitual, priorizam a apresentação do conteúdo de forma objetiva, com foco nas principais definições para os conceitos relativos ao tema, o que poderia justificar a presença majoritária desses modos.

A identificação dos modos presentes em cada uma das obras não foi suficiente para analisar a possível contribuição para a construção de significados, uma vez que a proporção de modos por página é semelhante entre eles. Assim, a análise mais elaborada dessa investigação consistiu na identificação das relações estabelecidas entre os diferentes modos empregados, conforme segue.

\section{b) As relações entre os modos semióticos}

Iniciamos esta parte de nossa exposição pelas relações existentes entre o modo escrita e os demais modos. As equações foram consideradas nos seus dois modos (matemáticas e químicas) já que as relações costumam se diferenciar nesses casos. Os demais, por comodidade de análise, foram mantidos em seus agrupamentos.

\section{Relação Texto/lmagem}

Analisamos cada uma das imagens presentes nas obras didáticas e a sua relação com o texto escrito. Organizamos os dados no Quadro 5, listando a quantidade de eventos verificada em cada livro analisado.

Para exemplificar cada uma dessas relações selecionamos uma imagem como representativa do que acontece nas demais imagens classificadas no mesmo grupo. Na Figura 2 exemplificamos uma relação direta entre texto e imagem e, na Figura 3, uma relação indireta entre esses dois modos semióticos.

Na Figura 2 podemos observar que, no primeiro parágrafo, há a identificação do ciclo da água como um fenômeno em que
Quadro 5: Relações entre texto e imagem, no trecho analisado.

\begin{tabular}{|l|c|c|c|}
\hline Relação & Livro 1 & Livro 2 & Livro 3 \\
\hline $\begin{array}{l}\text { Imagem diretamente relaciona- } \\
\text { da com o texto (com explicação } \\
\text { e referência) }\end{array}$ & - & 2 & 4 \\
\hline $\begin{array}{l}\text { Imagem indiretamente relacio- } \\
\text { nada com o texto (com explica- } \\
\text { ção, mas sem referência) }\end{array}$ & 2 & 2 & 2 \\
\hline $\begin{array}{l}\text { Imagem como exemplo (com } \\
\text { referência, mas sem explica- } \\
\text { ção) }\end{array}$ & 4 & 2 & 1 \\
\hline $\begin{array}{l}\text { Imagem ilustrativa (sem refe- } \\
\text { rência e sem explicação) }\end{array}$ & 32 & 5 & 8 \\
\hline
\end{tabular}

\section{Estados físicos e entalpia}

O ciclo da água - um fenômeno natural - constitui exemplo das mudanças de estado físico da matéria, bem como da energia envolvida nesses processos.

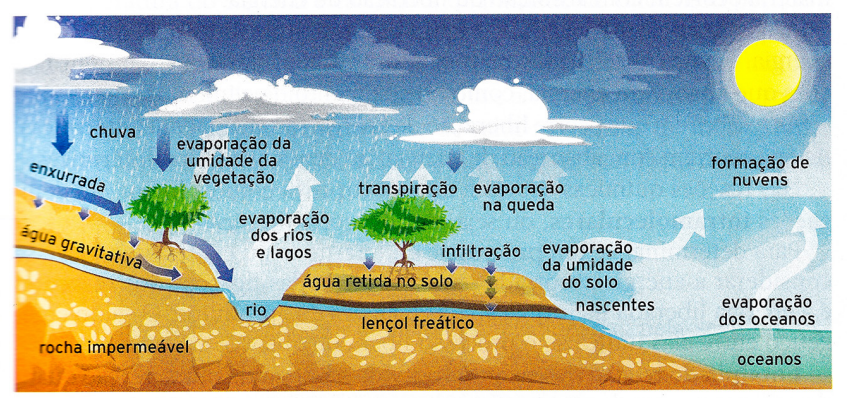

^ Esquema simplificado, em cores-fantasia, do ciclo da água.

processo de evaporação da água está relacionado com a energia térmica propagada pelo Sol e que incide na Terra. Para que esse processo corra, é necessário que haja absorção de energia. A formação das nuvens explicada pelo processo de condensação, o qual ocorre com liberação de energia

Figura 2: Exemplo de relação direta entre texto e imagem, Livro 2. Fonte: Lisboa et al., 2016, p. 53. 


\section{Entalpia e variação de entalpia}

Um dos fenômenos mais interessantes e intrigantes é a ebulição da água. No decorrer do processo, observa-se temperatura constante $\left(100^{\circ} \mathrm{C}\right.$ ao nível do mar) com mesmo fornecimento de energia.

Durante a ebulição, a energia fornecida reduz as interações intermoleculares presentes no líquido, originando o gás, que tem maior entalpia $(H)$. Sendo assim, há variação de entalpia $(\Delta H)$ no processo de transformação do estado líquido para o gasoso. A temperatura se mantém constante, pois a energia que seria utilizada para aumentar a temperatura é usada no rompimento das ligações intermoleculares.

A mudança de estado da água de líquido para gasoso pode ser representada pela seguinte equação.

\section{$\mathrm{H}_{2} \mathrm{O}(\ell)+$ energia $\longrightarrow \mathrm{H}_{2} \mathrm{O}(\mathrm{g})$}

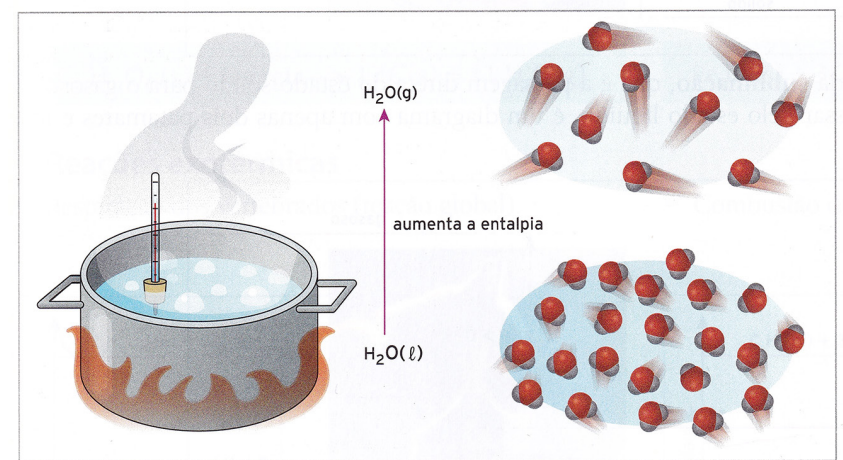

A Representação, em cores-fantasia, do fenômeno da ebulição da água.

Figura 3: Exemplo de relação indireta entre texto e imagem, Livro 2. Fonte: Lisboa et al., 2016, p. 57.

ocorrem as mudanças de estado físico. A imagem que o segue é acompanhada de uma espécie de legenda (Esquema simplificado, em cores-fantasia, do ciclo da água), identificando-a e o texto posterior à imagem explica os principais fenômenos presentes nessa imagem, relacionando-os à energia. Ao usar essa forma de relacionar texto e imagem, há o estabelecimento de uma relação direta entre esses dois modos, o que nos parece contribuir para o entendimento do leitor, que pode mais facilmente perceber a relação entre a explicação presente no texto e a imagem que acompanha essa explicação. Porém, alertamos que a relação ficaria mais explícita se o texto fizesse menção à figura.

Na Figura 3 os autores estão discutindo a ebulição da água, no texto escrito, e a imagem apresenta esse fenômeno acompanhado de uma linha que mostra a mudança de estado físico e de duas representações para as partículas no estado líquido e no estado gasoso, sem indicar diretamente a que se referem. Da maneira como estão organizados o texto e a imagem, cabe ao leitor fazer a relação que não foi feita pelos autores. Alves (2020), ao usar o eye-tracking para caracterizar os caminhos de leitura que um grupo de estudantes e de professores utilizou um texto multimodal e observou que esses caminhos não são padronizados. Com isso, acreditamos que ao indicar um caminho os autores estarão auxiliando o leitor no entendimento do texto, o que não aconteceu nos casos em que a relação é indireta e ocorreu parcialmente no caso escolhido como relação direta.

As Figuras 4 e 5, por sua vez, trazem exemplos de imagem ilustrativa e de imagem exemplificadora. Na Figura 4 os autores tratam de fontes energéticas e apresentam oito imagens sem fazer referências e sem explicá-las, o que nos levou a classificá-las como ilustrativas.

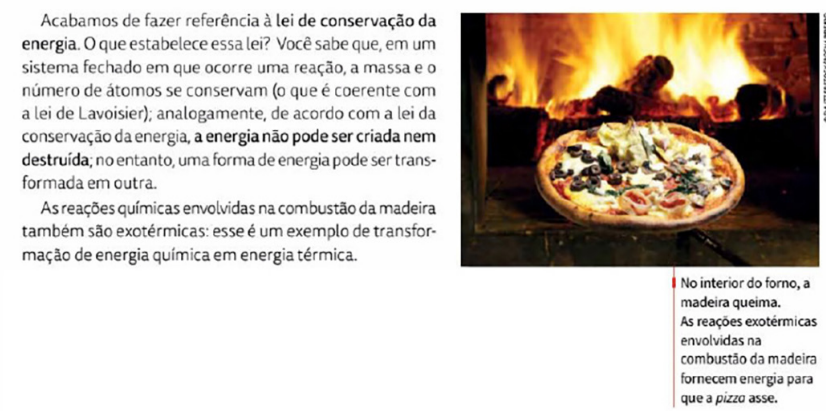

Figura 4: Exemplo de imagem meramente ilustrativa, Livro 3. Fonte: Novais e Antunes, 2016, p. 100.

Na p. 100 do livro de Novais e Antunes (2016), o assunto principal tratado envolve a classificação das reações químicas em endotérmicas e exotérmicas. Como podemos observar na Figura 4 , o texto se refere às reações de combustão e a figura lateral ao texto mostra uma pizza e, ao fundo, a madeira queimando. Percebe-se, de forma clara, que a imagem ilustra a combustão, sem que a linguagem verbal escrita se refira a imagem ou explique o seu significado. Vale ressaltar que assar o alimento (pizza) que está em destaque na imagem consome energia, o que evidencia a necessidade de explicar ou fazer a devida relação.

$\mathrm{Na}$ Figura 5 o texto escrito trata do biodigestor e, no parágrafo seguinte, próximo à imagem, retoma as reações de combustão.

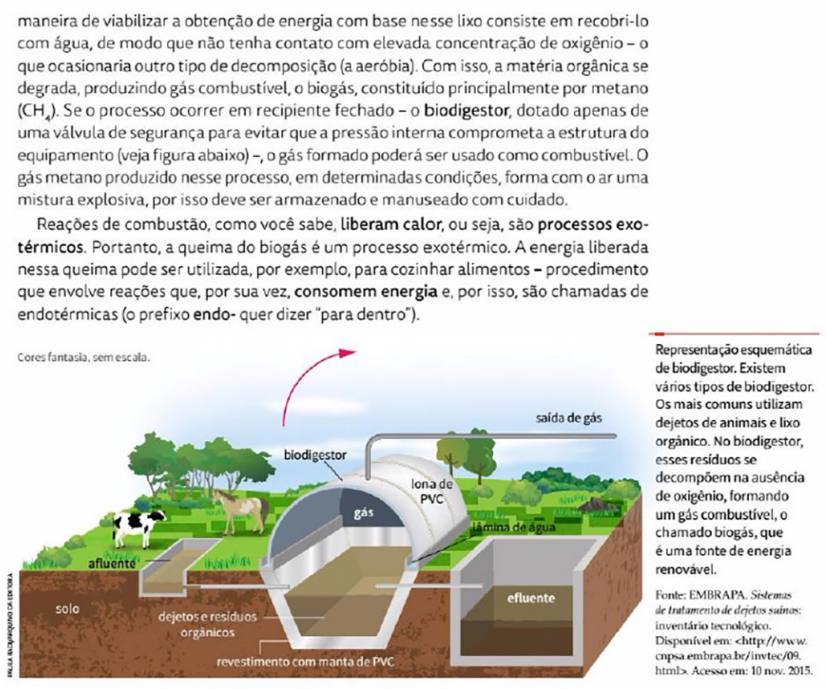

Figura 5: Relação exemplificadora entre texto e imagem, Livro 3. Fonte: Novais e Antunes, 2016, p. 97.

Na Figura 5, o texto escrito faz referência a imagem, ao inserir "(veja a figura abaixo)", o que pode indicar que os autores desejavam chamar a atenção do leitor para que fizesse uma observação mais atenta, relacionando a imagem ao texto. 
Esse tipo de indicação é importante principalmente quando a imagem não está imediatamente posterior ao texto. Alves (2020) enfatiza que os leitores optam, preferencialmente, por seguir a ordem do texto (de cima para baixo). Nesse caso, se não houver clara indicação, a imagem pode não ser relacionada ao texto que trata do mesmo assunto. Essa relação foi classificada como exemplificadora pelo fato de não haver qualquer tipo de explicação em relação ao funcionamento de cada etapa representada, ou seja, faz referência mas não explica.

\section{Relação entre Texto e Gráfico}

No caso dos gráficos presentes nas obras didáticas, analisamos a relação deles com o texto escrito. Organizamos os dados no Quadro 6, listando a quantidade de eventos verificada em cada livro analisado.

Quadro 6: Relações entre texto e gráfico, no trecho analisado.

\begin{tabular}{|l|c|c|c|}
\hline Relação & Livro 1 & Livro 2 & Livro 3 \\
\hline Relação Direta (com referência) & 8 & 5 & 2 \\
\hline $\begin{array}{l}\text { Relação Indireta (sem referên- } \\
\text { cia, mas explicado) }\end{array}$ & - & 2 & - \\
\hline $\begin{array}{l}\text { Gráfico llustrativo (sem referên- } \\
\text { cia e sem explicação) }\end{array}$ & 1 & 4 & - \\
\hline
\end{tabular}

Como é possível observar no Quadro 6, há estreita relação entre texto e gráfico nos livros analisados. A maior parte dos gráficos aparece referenciada nos textos que os acompanham e apresenta dados associados ao tema que é trabalhado no modo verbal. Para exemplificar essas relações, selecionamos dois trechos do Livro 1 que tratam do consumo de energia na sociedade. Os autores descrevem a evolução desse consumo ao longo de alguns séculos, em função de acontecimentos sociais que o provocaram.

0 consumo de energia na sociedade

Ademanda por maior quantidade de energia impulsionou o desenvolvimento, mais eficiente, de transformaçăo de energia. Assim, sucessivamente, passamos

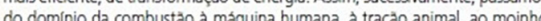
hidrálico da combustao a maquina humana, a traçao animal, ao moinh hidralico o devento a maquina avapor, atechegamos as a tuaisprocessos de produça te energia eletrica. Esses processos mais eficientes de produça de energia trouxeram aumento de qualidade de vida para a populaçăo.

A expansão dessa qualidade de vida implicou 0 aumento significativo do consumo de energia nos últimos séculos. Anteriormente, o aumento de consumo energético crescia muito lentamente. No século XIX, o crescimento aumentou cinco vezes e no século XX acelerou para um fator de dezesseis vezes, atingindo uma escala exponencial, sobretudo, depois da Segunda Guerra Mundial, mais precisamente na decada de 1940 (veja o gráfico ao lado).

Essa revolução ocorreu justamente com o avanç ecnológico, que substituiu a energia da biomass advinda da queima le lenha pela queima de combustive forseis pa queima da lenha pela queima de combustiveis Osseis potencialmente mais energeticos, como o carvào massivamente, desses combustiveis fosseis. Ocorre que

A Até o século XX não havia formas de se medir o consumo de energia, mas este pode ser estimado indicando um crescimento exponencial até o inicio deste século.

Figura 6: Exemplo de relação direta entre texto e gráfico, Livro 1. Fonte: Santos e Mol, 2016, p. 232.

Na Figura 6, o modo verbal escrito, que associa o consumo de energia ao aumento da qualidade de vida e essa ao aumento do consumo de energia, explica que no século XIX o consumo de energia aumentou cinco vezes e que no século XX esse aumento foi de 16 vezes, indicando que a informação pode ser vista no "gráfico ao lado". Esse gráfico mostra o consumo de energia ao longo de 20 séculos. As informações retiradas desse gráfico complementam as explicações fornecidas no texto permitindo ao leitor um melhor entendimento do assunto.

No Livro 1 há um único caso em que o gráfico serve apenas de ilustração ao tema tratado no texto. Isso acontece pelo fato desse gráfico não ser citado no texto e seus dados não serem explorados. A Figura 7 traz o fragmento do texto que apresenta esse gráfico.

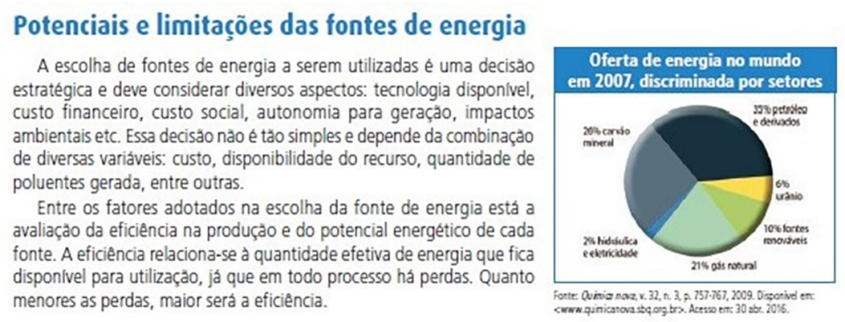

Figura 7: Exemplo de gráfico ilustrativo, Livro 1. Fonte: Santos e Mol, 2016, p. 239.

O texto aborda as diferentes fontes de energia disponíveis e alguns dos critérios que levam à escolha da fonte mais adequada. O gráfico que acompanha esse texto traz dados que representam a porcentagem de oferta de energia no mundo, por setores. Ainda que os temas de ambos os modos estejam associados, o texto não discorre especificamente sobre as fontes de energia citadas no gráfico, nem acerca dos valores nele apresentados. Em vista disso, certamente o leitor terá que fazer um esforço maior para entender a relação entre esses dois modos semióticos.

\section{Relação entre Texto e Equação Química}

As equações químicas são um modo de representação frequentemente utilizado na Química e, portanto, nos materiais didáticos a ela relacionados. Trata-se de um modo simplificado de descrever um determinado fenômeno, no qual reagentes e produtos são informados por meio de suas fórmulas químicas. No entanto, é uma linguagem bem específica da Ciência Química e de Ciências correlatas. O Quadro 7 exibe as relações entre equação química e texto existentes em cada livro didático investigado.

Quadro 7: Relações entre texto e equação química nos livros analisados.

\begin{tabular}{|l|c|c|c|}
\hline Relação & Livro 1 & Livro 2 & Livro 3 \\
\hline Relação direta & 4 & 5 & 12 \\
\hline Relação indireta & 4 & - & - \\
\hline
\end{tabular}

Observando o Quadro 7 constata-se que, quando há equação química, a maior parte das associações são realizadas de 
forma direta, ou seja, ou a equação química é referenciada no texto que a acompanha ou o texto menciona especificamente o fenômeno que é representado na equação química.

Usar dois modos semióticos diferentes para descrever um mesmo fenômeno pode auxiliar o estudante a se familiarizar com a simbologia própria da Química. No entanto, a percepção de que realmente se trata do mesmo fenômeno tende a acontecer mais facilmente se esses modos estiverem diretamente relacionados. Para exemplificar momentos em que há essa relação, selecionamos dois fragmentos. No primeiro (Figura 8) são apresentadas as reações exotérmicas e o exemplo usado é a combustão do etanol. Em seguida, é exibida a equação química referente a essa combustão, indicando abaixo de cada fórmula molecular o nome da substância.

\section{Transformações exotérmicas}

Reações exotérmicas são aquelas que liberam calor para o ambiente; as combustões são exemplos desse tipo de reação, sendo largamente empregadas em nosso dia a dia justamente por isso. Um exemplo de uso bastante conhecido é a queima do etanol (usado como combustivel em automóveis). A equação que representa essa transformação exotérmica é:

$$
\underset{\substack{\text { etanol } \\
\text { (combustivel) }}}{\mathrm{C}_{2} \mathrm{H}_{6} \mathrm{O}(\mathrm{l})}+\underset{\begin{array}{c}
\text { oxigênio } \\
\text { (comburente) }
\end{array}}{3 \mathrm{O}_{2}(\mathrm{~g})} \underset{\substack{\text { dióxido de } \\
\text { carbono }}}{2 \mathrm{CO}_{2}(\mathrm{~g})}+\underset{\text { água }}{3 \mathrm{H}_{2} \mathrm{O}(\mathrm{g})}+\text { calor }
$$

Nesse caso, conforme a lei de conservação da energia, a energia inicial do sistema etanol + oxigênio é maior do que a energia final do sistema dióxido de carbono + água, já que certa quantidade de energia foi liberada para o ambiente na forma de calor.

Reação exotérmica: $E_{\text {reagentes }}>E_{\text {produtos }}$

Figura 8: Exemplo de relação direta entre texto e equação química, Livro 3. Fonte: Novais e Antunes, 2016, p. 99.

Essa relação direta entre o texto e a equação química está bem explicitada, já que todos os reagentes e produtos envolvidos estão identificados e o texto trata deles. Assim, o leitor consegue identificar todas as substâncias envolvidas. Diferentemente dessa relação, na Figura 9 destacamos um fragmento do Livro 1, em que a equação química apresenta um fenômeno que não está especificado no texto.

Lembre-se, portanto, que as reaçoes químicas podem ser acompanhadas de liberaçăo ou absorçầo de energia, normalmente ocorrida na forma de calor. Quando há liberaçào de calor, a reação é denominada reaçào exotérmica; quando a reaça absorve calor, recebe o nome de endotérmica Observe que o prefixo exo significa "para fora" e o prefixo endo, "para dentro".

Podemos representar a variaçào de energia de reaçoes químicas, a partir de diagramas que indicam os niveis de energia de seus reagentes e de seus produtos.

Veja, por exemplo, a reaçăo endotérmica:

$$
\mathrm{N}_{2}(\mathrm{~g})+\mathrm{O}_{2}(\mathrm{~g}) \rightarrow 2 \mathrm{NO}(\mathrm{g})
$$

Figura 9: Exemplo de relação indireta entre texto e equação química, Livro 1. Fonte: Santos e Mol, 2016, p. 260.

Ainda que a equação química apresentada como exemplo esteja coerente com o conteúdo do texto (reação endotérmica), percebe-se que não há menção ao fenômeno de síntese do monóxido de nitrogênio. Nesse caso a equação química foi apresentada apenas para exemplificar um conceito geral que aborda a energia envolvida nas transformações químicas.
O estudante pode não reconhecer o fenômeno presente nessa equação.

\section{Relação entre o Texto e as Equações Matemáticas}

O conteúdo que tratava de entalpia, que tradicionalmente tem fórmulas para o cálculo da energia envolvida em uma reação química, não foi incluído nessa análise. Porém, algumas equações matemáticas foram identificadas ao longo do conteúdo investigado. O Quadro 8 traz os tipos de relação, listando a quantidade de eventos verificada em cada livro analisado.

Quadro 8: Relações entre texto e equação matemática nos livros analisados.

\begin{tabular}{|l|c|c|c|}
\hline Relação & Livro 1 & Livro 2 & Livro 3 \\
\hline Relação completa & 4 & 2 & 2 \\
\hline Relação incompleta & 1 & 1 & - \\
\hline
\end{tabular}

Consideramos que as relações completas entre texto e equação matemática podem auxiliar o leitor a compreender as variáveis que fazem parte daquele contexto e reduzir os enganos, ao se empregar valores referentes a cada um dos termos. Nós observamos que, na maior parte das equações matemáticas, cada termo constituinte da equação está devidamente identificado no texto que a acompanha. Para exemplificar essas relações, o Livro 3 (Novais; Antunes, 2016, p. 103) apresenta a equação $Q=m \times c \times \Delta t$ e descreve o significado de cada um dos símbolos que compõe a equação. Já no Livro 1, é tratado da capacidade calorífica de um corpo e é apresentada a equação matemática $C=m \times c$. Porém, não há indicação do significado de cada um dos símbolos presentes na equação.

\section{Relação entre o Texto e as Tabelas}

Tabelas são recursos geralmente utilizados com o objetivo de sintetizar uma série de informações referentes a algum assunto específico. Esse modo semiótico pode ter seus dados discutidos no texto (relação direta) ou ser exibido como uma fonte de informações complementares, sem que seja realizada uma análise do conteúdo comunicado pela tabela (ilustrativa).

Com exceção do Livro 3, que não possui tabelas no trecho selecionado para análise, a relação mais recorrente identificada entre texto e tabela não envolve a discussão dos dados que nela são apresentados. As tabelas foram, majoritariamente, ilustrativas, como pode ser observado no Quadro 9.

Quadro 9: Relações entre texto e tabelas, nos livros analisados.

\begin{tabular}{|l|c|c|c|}
\hline Relação & Livro 1 & Livro 2 & Livro 3 \\
\hline Relação direta & 1 & - & - \\
\hline Tabela ilustrativa & 3 & 1 & - \\
\hline
\end{tabular}

Em um contexto de cálculo de quantidade de calor, que envolve o uso de valores referentes a uma propriedade identificada 


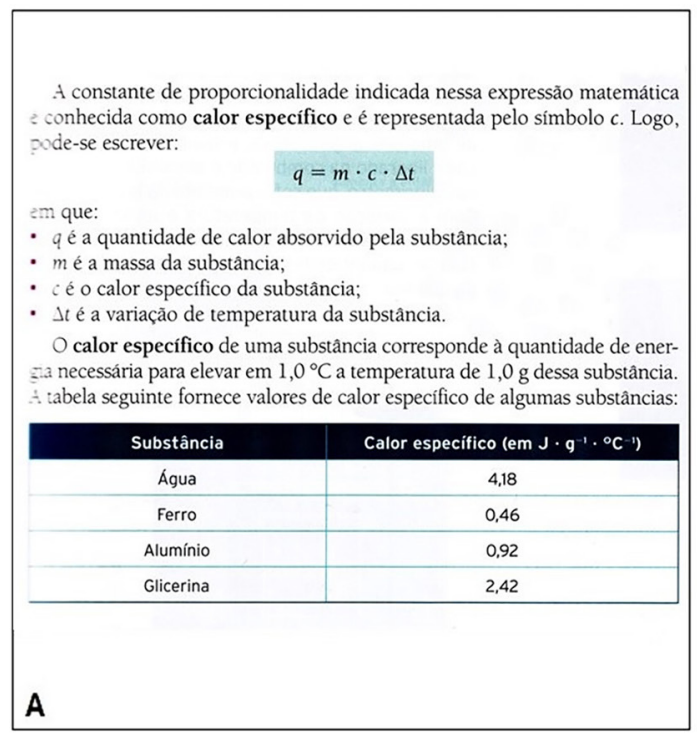

\begin{tabular}{|c|c|}
\hline \multicolumn{2}{|c|}{ 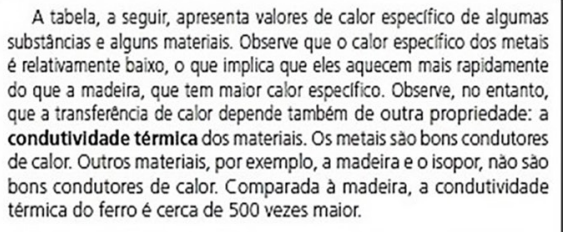 } \\
\hline \multicolumn{2}{|c|}{$\begin{array}{l}\text { CALORES ESPECIFCOS DE ALCUMAS } \\
\text { SUBSTANGIAS E MAIERIAIS }\end{array}$} \\
\hline Substância/material & Calor especifico \\
\hline Aluminio(s) & $0,903 / \mathrm{g}^{-10} \mathrm{C}^{-1}$ \\
\hline Ferro(s) & $0,449 \mathrm{Jg}^{-10} \mathrm{C}^{-1}$ \\
\hline Cobre(s) & $0,385 / \mathrm{g}^{-10} \mathrm{C}^{-1}$ \\
\hline Agua(1) & $4,178 \mathrm{Jg}^{-10} \mathrm{CO}^{-1}$ \\
\hline Etanol(1) & $2,419 \mathrm{~J} \mathrm{~g}^{-10} \mathrm{C}-1$ \\
\hline Madeira $^{*}$ & $1,66] \mathrm{g}^{-10} \mathrm{C}^{-1}$ \\
\hline Chumbo(s) & $0,128 \mathrm{~J} \mathrm{~g}^{-18} \mathrm{C}^{-1}$ \\
\hline
\end{tabular}

Figura 10: Exemplo de relações entre texto e tabela, Livros 1 e 2 ( $\mathrm{A}$ = ilustrativa; $B$ = direta). Fonte: Lisboa et al., 2016 , p. 55 (A), Santos e Mol, 2016, p. 252 (B).

como Calor Específico, é possível observar, na Figura 10, dois exemplos de texto, sendo que um deles apresenta os dados sem explorá-los (A) enquanto o outro explica os dados (B), oferecendo um suporte ao leitor para facilitar o entendimento.

Nesses casos, há uma nítida diferença em como os dados da tabela são tratados nas diferentes obras. Enquanto uma tabela (A) tem a função de exemplificar valores de calor específico de alguns materiais, a outra (B) usa o texto verbal para comparar valores e apresenta algumas implicações desses valores no cotidiano, como foi o caso do aquecimento de materiais. Com isso, é provável que o leitor se sinta mais familiarizado com os dados e, assim, os valorize mais.

\section{Relação entre Texto e Boxe}

As caixas de texto destacadas, presentes em alguns livros, trazem aspectos históricos (boxe-história), definição de conceitos (boxe-conceito), retomam um conceito já trabalhado (boxe-retomando conceitos) e aspectos referentes a ações cidadãs (boxe-ação e cidadania). Para esses casos, apresentamos no Quadro 10 apenas as relações entre o texto geral e os textos presentes nas "caixas".
Uma vez que essas caixas estão presentes, é esperado que elas sejam objeto de leitura. Para isso, é indicado que o(s) autor(es) faça(m) a indicação dessa leitura no texto geral, de forma que o estudante perceba o momento em que esse boxe se relaciona com o conteúdo que ele está estudando. Porém, como elas estão em número reduzido quando comparado com os outros modos semióticos, o resultado dessa análise é limitado. Continuamos, no entanto, argumentando que a presença de uma relação explícita desses textos com o texto principal fornece mais sentido a esse modo.

\section{Outras Relações Encontradas: Gráfico/lmagem e Gráfico/Equação Química}

Considerando que os livros 3 e 4 não trazem os modos semióticos gráfico e imagem, de forma simultânea, para tratar do mesmo tema, e que o Livro 1 não apresenta os modos gráfico e equação química, de forma simultânea, as relações acabam por se reduzir a poucos exemplos. Por isso, optamos por analisá-las conjuntamente. O Quadro 11 traz essas relações.

Para exemplificar, selecionamos um fragmento de um dos livros, que traz as relações feitas pelos autores. Na Figura 11

Quadro 10: Relações entre texto e boxe, presentes nos livros.

\begin{tabular}{|c|c|c|c|c|}
\hline \multicolumn{2}{|l|}{ Relação } & \multirow{2}{*}{$\frac{\text { Livro } 1}{-}$} & \multirow{2}{*}{$\begin{array}{c}\text { Livro } 2 \\
-\end{array}$} & \multirow{2}{*}{$\begin{array}{c}\text { Livro } 3 \\
-\end{array}$} \\
\hline \multirow{3}{*}{ Boxe referenciado no texto } & Boxe-história & & & \\
\hline & Boxe-conceito & 8 & - & - \\
\hline & Boxe-ação e cidadania & - & - & - \\
\hline \multirow{3}{*}{ Boxe não referenciado no texto } & Boxe-história & 1 & 1 & - \\
\hline & Boxe-relembrando conceitos & - & 2 & - \\
\hline & Boxe-ação e cidadania & 1 & 2 & - \\
\hline
\end{tabular}


Quadro 11: Relação gráfico/imagem e Gráfico/equação química.

\begin{tabular}{|l|c|c|c|}
\hline Relação & Livro 1 & Livro 2 & Livro 3 \\
\hline $\begin{array}{l}\text { Gráfico e Imagem representam } \\
\text { o mesmo fenômeno }\end{array}$ & - & 5 & - \\
\hline $\begin{array}{l}\text { Gráfico e equação química re- } \\
\text { presentam o mesmo fenômeno }\end{array}$ & 4 & 5 & 2 \\
\hline
\end{tabular}

a relação se dá entre o gráfico, a imagem e a equação química.

Na Figura 11 são apresentadas quatro situações em que a imagem se relaciona com o fenômeno representado no gráfico, acompanhado da equação química, em cada caso. Pela proximidade em que esses diferentes modos se encontram, é esperado que o leitor tenha facilidade em relacioná-los. As imagens presentes trazem informações que não estão explícitas, mas que podem ser exploradas no texto escrito.

\section{O que essas relações nos dizem?}

Nossas análises confirmaram a natureza multimodal da comunicação. Os três livros fazem uso de vários modos semióticos e as imagens são as que mais apareceram, representando cerca de 50,5\% desse uso (não considerando a escrita). Porém, essas imagens são majoritariamente utilizadas como ilustração, ou seja, a imagem está presente, mas poucas vezes é referenciada no texto escrito ou explicada pelos autores.

A presença dessas imagens em textos didáticos é uma característica crescente da contemporaneidade. O desenvolvimento das tecnologias proporcionou e facilitou a geração de imagens em muitas Ciências contemporâneas, como é o caso da Astronomia, da Bioquímica e de outras Ciências para as quais as imagens se tornaram essenciais. Isso também aconteceu nos livros didáticos que hoje são mais coloridos e mais detalhados em termos de representação, dentre outras inovações/características.

Temos plena convicção de que o uso de imagens auxilia no processo de construção do conhecimento, uma vez que possibilita aos estudantes um entendimento mais amplo do que antes era ancorado quase que exclusivamente no texto escrito. No entanto, é indicado que esses diferentes modos estejam diretamente relacionados entre si de forma que o estudante perceba que os diferentes modos semióticos estão representando o mesmo fenômeno. Observamos que há casos em que essa relação está clara nos textos didáticos. Em outros, porém, isso não acontece. Acreditamos que, ao dedicarmos atenção aos textos didático-científicos presentes nos livros didáticos,

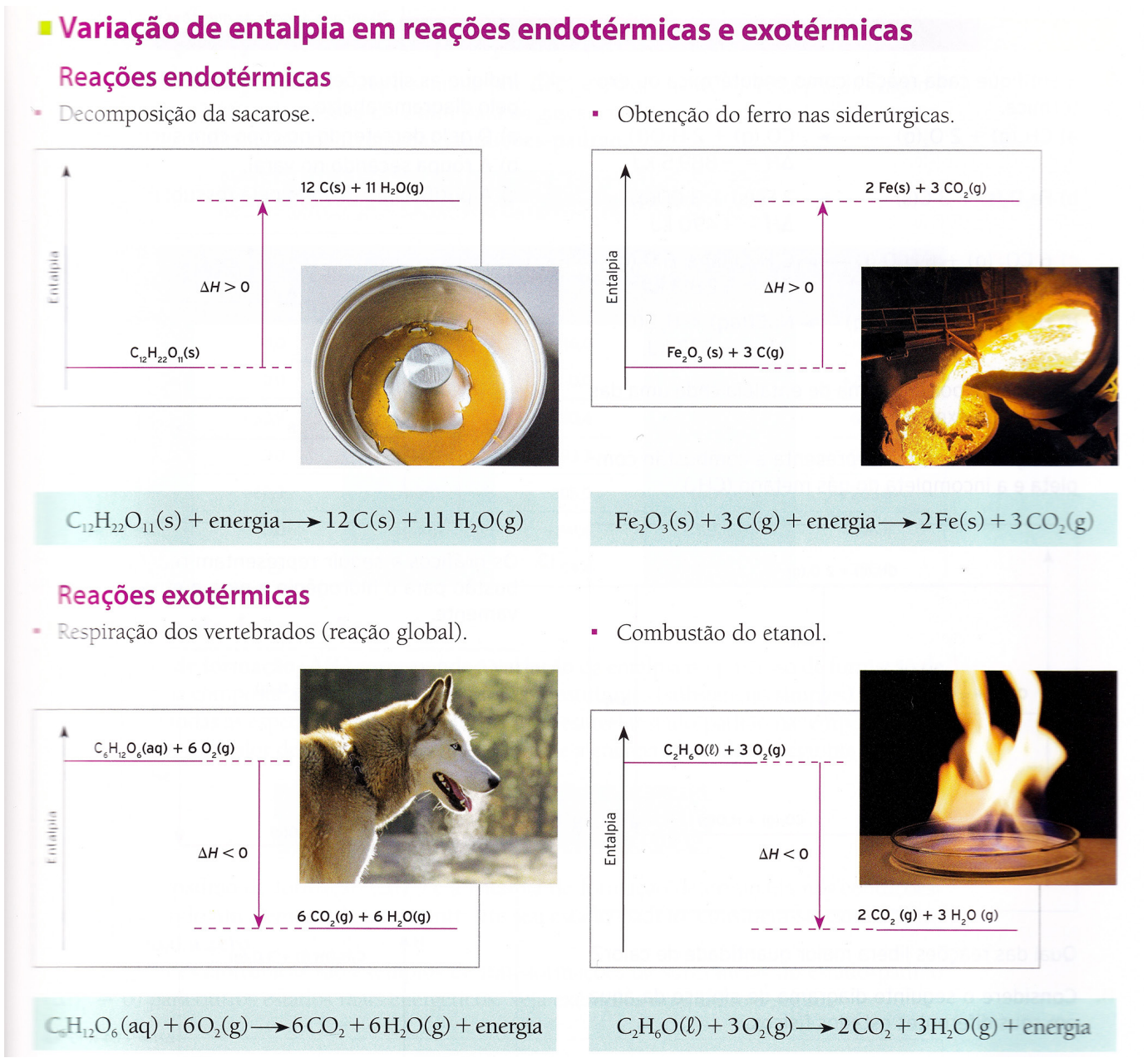

Figura 11: Gráficos/Imagens/Equações químicas, Livro 2. Fonte: Lisboa et al., 2016, p. 59. 
podemos identificar possibilidades para melhorá-los ainda mais.

Nos casos em que os autores optaram por inserir em seus livros didáticos modos semióticos do tipo boxe (história, ação e cidadania, conceito, relembrando conceito), a análise feita mostrou que esses modos se relacionam com o texto escrito de forma restrita, sendo constituídos por temas que se relacionam ao conteúdo trabalhado ao longo do texto. Porém, trata-se de uma relação implícita, que poderia ser explicitada, para facilitar e aprofundar o conhecimento do próprio estudante.

As relações entre texto e gráfico, texto e equação química e texto e equação matemática, também aparecem com certa frequência e, em sua maioria, são estabelecidas de forma bem conectada ao longo das discussões. Nesse caso, é importante que o texto escrito apresente com detalhes aquilo que um gráfico ou uma equação desejam representar, pois a linguagem específica desses modos deve se tornar familiar para os estudantes, que poderão, assim, desenvolver novas habilidades de interpretar e compreender esses modos de forma mais autônoma.

Optamos por analisar os trechos referentes à parte inicial do conteúdo de Termoquímica, nos livros didáticos. Acreditamos que os resultados encontrados na análise desses trechos representam o que é a obra como um todo. À medida que entendemos a importância em relacionar esses modos, podemos fomentar essas relações nas aulas que desenvolvemos, acreditando que elas podem ser ampliadas nos livros didáticos.

\section{Referências}

ABNT. Associação Brasileira De Normas Técnicas. NBR 14724: Informação e documentação - Trabalhos acadêmicos - Apresentação. ( $3^{\mathrm{a}}$ ed.) Rio de Janeiro, 2011.

ALVES, E. G. Um estudo multimodal de textos didáticos sobre o efeito fotoelétrico. 30 ago. 2011. 132 p. Dissertação (Mestrado em Educação). Faculdade de Educação, Universidade Federal de Minas Gerais, 2011.

ALVES, E. G. Utilizando o eye-tracking para caracterizar os caminhos. Tese (Doutorado em Educação). Faculdade de Educação, Universidade Federal de Minas Gerais, 2020.

ALVES, E. G. e MORTIMER, E. F. Integração de diferentes modos semióticos em textos multimodais de livros didáticos de Física: considerações sobre o caminho de leitura. XI ENCONTRO NACIONAL DE PESQUISA EM EDUCAÇÃO EM CIÊNCIAS, 2017. Anais... Florianópolis-SC, 2017, p. 1-14.

AMARAL, I. A. e MEGID NETO, J. Qualidade do livro didático de Ciências: o que define e quem define? Ciência \& Ensino, n. 2, p. 13-14, 1997.

BRASIL, Ministério da Educação. Secretaria da Educação Básica. Fundo Nacional de Desenvolvimento da Educação. Secretaria da Educação Básica, Edital de Convocação No 03/2019 - CGPLI. Diário Oficial da União, seção 3, $N^{\circ} 176,11$ de setembro de 2019, Disponível em https://www.fnde.gov.br/index.php/programas/programas-do-livro/ consultas/editais-programas-livro/item/13106-edital-pnld-2021, acesso em mai. 2020.
BRASIL. Ministério da Educação. Secretaria da Educação Básica. Fundo Nacional de Desenvolvimento da Educação. PNLD 2018: Guia de livros didáticos - Ensino Médio. Brasília, 2017. 38 p. Disponível em: http://www.fnde.gov.br/pnld-2018/index.html, acesso em set. 2018

CARNEIRO, M. H. S.; SANTOS, W. L. P. e MÓL, G. S. Livro didático inovador e professores: uma tensão a ser vencida. Ensaio: Pesquisa em Educação em Ciências, v. 7, n. 2, p. 101-113, mai-ago/2005.

FRISON, M. D.; VIANNA, J.; CHAVES, J. M. e BERNARDI, F. N. Livro didático como instrumento de apoio para construção de propostas de ensino de Ciências Naturais. In: VII ENCONTRO NACIONAL DE PESQUISA EM EDUCAÇÃO EM CIÊNCIAS, 8 a 13 de novembro de 2009, Florianópolis-SC. Anais ... FlorianópolisSC, 2009, p. 1-13.

GIORDAN, M. O papel da experimentação no Ensino de Ciências. Química Nova na Escola, n. 10, p. 43-49, 1999.

GuimarÃeS, L. P.; CASTRO, D. L.; LiMA, V. e ANJOS, M. Ensino de Ciências e experimentação: reconhecendo obstáculos e possibilidades das atividades investigativas em uma formação continuada. Revista Thema, v. 15, n. 3, p. 1164-1174, 2018.

JOYCE, H. S. e FEEZ, S. Multimodality across classrooms: learning about and through different modalities. Routledge, 2018.

KRESS, G. Multimodality: a social semiotic approach to contemporary communication. London and New York: Routledge, 2010.

KRESS, G.; JEWITT, C.; OGBORN, J. e TSATSARELIS, C. Multimodal Teaching and Learning: The rhetorics of the science classroom. 1 ed. London and New York: Continuum, 2001.

LAJOLO, M. Livro didático: um (quase) manual do usuário. Em aberto, v. 16, n. 69, p. 3-9, 1996.

LOBATO, A. C.; SILVA, C. N.; LAGO, R. M.; CARDEAL, Z. L. e QUADROS, A. L. Dirigindo o olhar para o efeito estufa nos livros didáticos de ensino médio: é simples entender esse fenômeno? Ensaio: Pesquisa em Educação em Ciências, v. 11, n. 01, p. 07-24, 2009.

MILLAR, R. Um currículo de ciências voltado para a compreensão por todos. Ensaio: Pesquisa em Educação em Ciências, v. 5, n. 2, p. 73-91, 2003.

MORTIMER, E. F. A evolução dos livros didáticos de química destinados ao ensino secundário. Em aberto, ano 7, n. 40, p. 25-41, 1988.

MORTIMER, E. F. e QUADROS, A. L. Multimodalidade no ensino superior. Ijuí: Ed. UNIJUÍ, 2018.

MUNFORD, D. e LIMA, M. E. C. C. Ensinar ciências por investigação: em quê estamos de acordo? Ensaio: Pesquisa em Educação em Ciências, v. 9, n. 1, p. 89-111, 2007.

MEGID NETO, J. e FRACALANZA, H. O livro didático de Ciências: problemas e soluções. Ciência \& Educação, v. 9, n. 2, p. 147-157, 2003.

NORRIS, S. Analyzing Multimodal Interaction: a methodological framework. 1 ed. New York: Routledge, 2004.

PINHEIRO, N. A. M.; SILVEIRA, R. M. C. F. e BAZZO, W. A. Ciência, tecnologia e sociedade: a relevância do enfoque CTS para o contexto do Ensino Médio. Ciência \& Educação, v. 13, n. 1, p. 71-84, 2007.

QUADROS, A. L.; PENA, D. M. B. e BOTELHO, M. L. S. T. As Representações Multimodais: construto teórico. In: QUADROS, 
A. L. (org.). Representações multimodais no ensino de ciências: compartilhando experiências. Curitiba: Ed. CRV, 2020.

SANTOS, W. L. P. e MORTIMER, E. F. Uma análise de pressupostos teóricos da abordagem C-T-S (Ciência - Tecnologia - Sociedade) no contexto da educação brasileira. Ensaio: Pesquisa em Educação em Ciências, v. 2, n. 2, p. 119-132, 2000.

SILVA, S. P.; SOUZA, F. E. B. e CIPRIANO, L. C. Textos multimodais: um novo formato de leitura. Linguagem em (Re)vista, Niterói, v. 10, n. 19, p. 133-159, 2015.

STRIEDER, R. B. Abordagens CTS na educação científica no Brasil: sentidos e perspectivas. 2012. Tese (Doutorado em Ensino de Ciências), Universidade de São Paulo, São Paulo, 2012.

TRIVELATO, S. L. F. e TONIDANDEL, S. M. R. Ensino por Investigação: eixos organizadores para sequências de Ensino de Biologia. Ensaio: Pesquisa em Educação em Ciências, v. 17, n. esp., p. 97-114, 2015.

ZÔMPERO, A. F. e LABURÚ, C. E. Atividades investigativas no Ensino de Ciências: aspectos históricos e diferentes abordagens. Ensaio: Pesquisa em Educação em Ciências, Belo Horizonte, v. 13, n. 3, p. 67-80, 2011. 